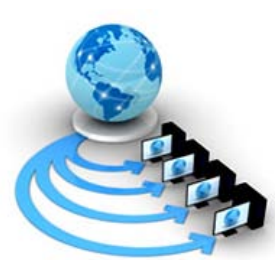

Volume 8, No. 8,September-October 2017

International Journal of Advanced Research in Computer Science

RESEARCH PAPER

Available Online at www.ijarcs.info

\title{
DEVELOPING SURVEILLANCE CHALLENGES IN THE INTERNET OF THINGS (IOT)
}

\author{
M. Shankar Lingam \\ University of Mysore, \\ Mysore,India
}

\author{
Raghavendra GS \\ Research Scholar, BIMS, \\ University of Mysore, \\ Mysore,India
}

\author{
Dr.A. M. Sudhakara \\ Director \\ Centre for Information Science Technology (CIST) \\ University of Mysore, \\ Mysore,India
}

\begin{abstract}
The day when certainly every electronic tool-from telephones and automobiles to refrigerators and mild switches-can be related to the Internet isn't always a long way away. The wide variety of Internet-linked gadgets is growing hastily and is anticipated to reach 50 billion by 2020. However modern and promising it appears, this so-known as Internet of Things (IoT) phenomenon notably will increase the range of security risks corporations and consumers will unavoidably face. Any device connecting to the Internet with an running system comes with the possibility of being compromised, becoming a backdoor for attackers into the agency.

In this selection, the proliferation of the Internet of Things and explore what firms can do to manipulate the security dangers related to IoT devices.
\end{abstract}

Keywords: Internet of Things, Security Concerns, Vulnerability Management, Security Controls

\section{GROWING IN POPULARITY THE IOT}

The IoT sensation is rapidly embracing whole societies and holds the capability to empower and increase almost everyand each man or woman and enterprise. This creates exceptional opportunities for firms to expand new services and products that provide extended comfort and pride to their consumers.[1][21]

On the consumer side, Google lately introduced that it is partnering with essential automakers Audi, General Motors and Honda to position Android-connected cars on the roads. Google is currently growing a new Android platform that connects these automobiles to the Internet. Soon, automobile owners could be able to lock or unencumber their motors, start the engine or even reveal vehicle performance from a computer or cellphone.

The guarantees of IoT pass a long way beyond the ones for man or woman customers. Enterprise mobility management is a hastily evolving example of the effect of IoT gadgets. Imagine if suddenly each package delivered for your enterprise came with a integrated RFID chip that would connect with your internet paintings and discover itself to a related logistics gadget. Or photo a medical environment in which every instrument within the exam room is attached to the community to transmit patient information collected thru sensors. Even in industries like farming, imagine if every animal had been digitally tracked to reveal its place, health and conduct. The IoT opportunities are infinite, and so is the quantity of devices that might manifest.[2][17]

However, no matter the opportunities of IoT, it additionally comes with many risks. Any tool which could hook up with
Internet has an embedded working device deployed in its firmware. Because embedded running systems are often now not designed with safety as a primary do not consideration, vulnerabilities are found in really they all- simply look at the quantity of malware that is targeting Android-based devices today. Similar threats will probable proliferate amongst IoT gadgets as they seize on.[17]

Enterprises and users alike should be prepared for the several issues of IoT. Listed underneath are seven of the many dangers which can be inherent in an Internet of Things global, as well as suggestions to assist groups prepare for the assignment. [3]

\section{DISRUPTION AND DENIAL-OF-SERVICE ATTACKS}

Ensuring non-stop availability of IoT-based totally devices is critical to avoid capability operational disasters and interruptions to agency offerings. Even the seemingly simple process of including new quit factors into the network-in particular automated devices that work under the precept of machine-to-machine communications like those who help run electricity stations or construct environmental controlscalls for corporations to focus attention on bodily assaults at the devices in remote locations. As a result, the commercial enterprise ought to reinforce physical safety to save you unauthorized get admission to to devices outdoor of the safety perimeter.[4]

Disruptive cyber assaults, including disbursed denial-ofprovider assaults, ought to have new unfavorable outcomes for a company. If lots of IoT gadgets attempt to get 
admission to a company internet site or statistics feed that isn’t available, formerly glad clients turns into frustrated, ensuing in revenue loss, customer dissatisfaction and doubtlessly negative reception in the market.[19]

Many of the challenges inherent to IoT are just like those observed in a convey your own device surroundings. Capabilities for managing misplaced or stolen gadgetseither far off wiping or at the least disabling their connectivity-are vital for dealing with compromised IoT gadgets. Having this employer strategy in region allows mitigate the risks of corporate statistics finishing up in the incorrect hands. Other guidelines that help control bring your own device could also be beneficial.[20]

\section{UNDERSTANDING THE COMPLEXITY OF VULNERABILITIES}

Last year, an unknown attacker used a recognized vulnerability in a popular Web-related infant monitor to spy on a two-year-antique. This eye-establishing incident goes to reveal what an excessive danger the IoT poses to establishments and purchasers alike. In a greater dramatic enough, consider the use of an IoT tool like an easy thermostat to control temperature readings at a nuclear electricity plant. If attackers compromise the tool, the consequences will be devastating. Understanding wherein vulnerabilities fall at the complexity meter-and how critical of a danger they pose-goes to emerge as a large predicament. To mitigate the chance, any venture regarding IoT devices ought to be designed with safety in thoughts, and incorporate safety controls, the usage of a pre-built position-based totally security version. Because these devices have hardware, systems and software that organizations might also in no way have seen earlier than, the varieties of vulnerabilities may be not like whatever agencies have dealt with formerly. It's important now not to underestimate the accelerated danger many IoT devices may also pose.[5][20]

\section{IOTVULNERABILITY MANAGEMENT}

Another large venture for companies in anIoT surroundings is identifying a way to quickly patch IoT device vulnerabilities — and how to prioritize vulnerability patching. Because maximum IoT devices require a firmware update to patch vulnerabilities, the mission may be complex to accomplish on the fly. For example, if a printer calls for firmware upgrading, IT departments are not going if you want to practice a patch as quickly as they could in a server or laptop machine; upgrading custom firmware frequently requires extra effort and time. [6][18].

\section{Application of IOT}

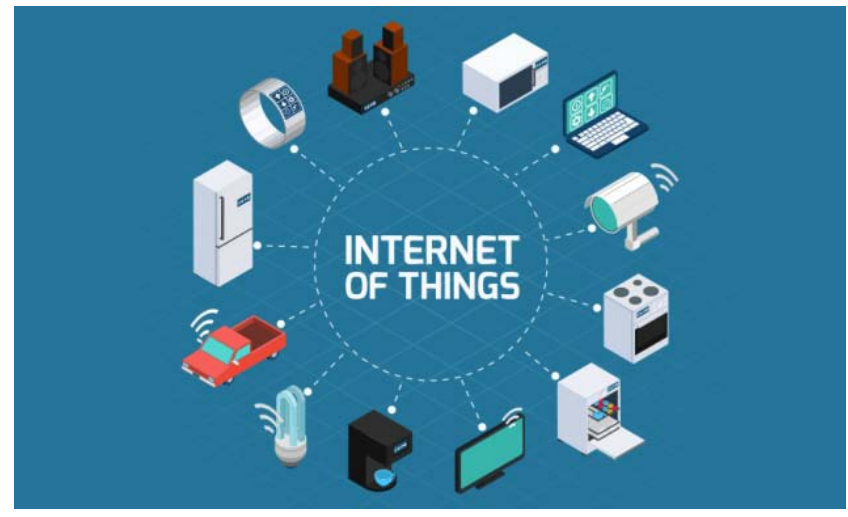

Also difficult for companies is coping with the default credentials supplied whilst IoT devices are first used. Often, devices along with wi-fi get right of entry to factors or printers include recognised administrator IDs and passwords. On top of this, gadgets may additionally provide a integrated Web server to which admins can remotely join, $\log$ in and control the device. This is a big vulnerability which can put IoT gadgets into attackers' palms. This calls for businesses to broaden a stringent commissioning system. It also requires them to create a development environment wherein the initial configuration settings of the devices can be tested, scanned to become aware of any sort of vulnerabilities they present and proven, allowing the enterprise to address mayissues before the device is moved into the seasoneducation surroundings. This similarly requires a compliance team to certify that the device is ready for manufacturing, take a look at the security control on a periodic basis and ensure that any changes to the device are intently monitored and managed and that any operational vulnerabilities found are addressed directly.[7]

Security in IOT

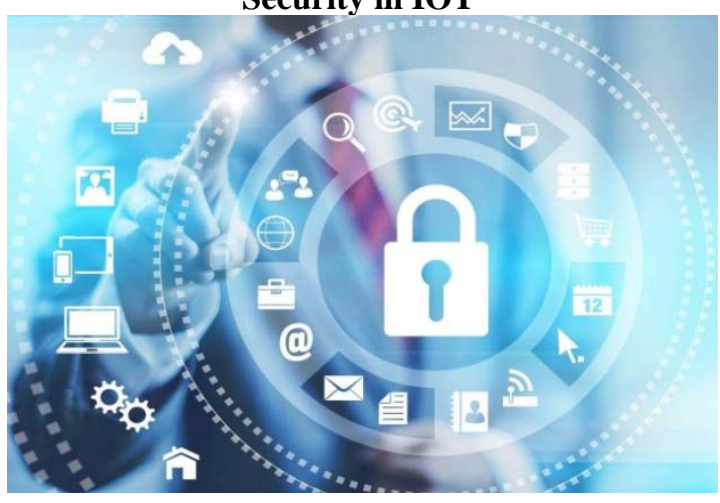

\section{IDENTIFYING, IMPLEMENTING SECURITY CONTROLS}

In the IT global, redundancy is important; should one product fail, every other is there to take over. The idea of layered protection works in addition, however it remains to be visible how nicely organisations can layer security and redundancy to control IoT threat. For instance, within the healthcare industry, clinical gadgets are to be had that now not simplest display sufferers' health statuses, but additionally dispense medicinal drug based totally on evaluation these devices perform. It's clean to imagine how tragic consequences ought to result if these devices became compromised. [8][16] 
The challenges for companies lie in figuring out where protection controls are wanted for this rising breed of Internet-linked gadgets, and then enforcing effective controls. Given the diversity that exists among these devices, businesses must conduct custom designed risk exams to pick out the dangers and determine how fine to incorporate them. [8]

A thrilling recent instance turned into the case of former Vice President Dick Cheney disabling the far off connectivity of a defibrillator implanted in his chest. Unfortunately most organisations don't have the luxurious of taking those gadgets offline. In any occasion, agencies that include IoT need to outline their own information safety controls to make sure the desirable and ok safety of the IoT evolution. As the fashion matures, quality practices will without a doubt emerge from enterprise professionals.[9]

\section{FULFILLING THE NEED FOR SECURITY ANALYTICS CAPABILITIES}

The range of new Wi-Fi-enabled devices connecting to the Internet creates a flood of facts for companies to collect, aggregate, method and examine. While companies can perceive new business opportunities based in this facts, new risks turn out to be well.

With all of this facts, businesses need to be able to discover legitimate and malicious visitors patterns on IoT devices. For instance, if an worker tries to download a seemingly legitimate app onto a smartphone that contains malware, it is critical to have actionable hazard intelligence measures in location to pick out the risk. The satisfactory analytical tools and algorithms now not handiest stumble on malicious hobby, but also improve customer support efforts and enhance the offerings being provided to the customers. [10]

To prepare for these demanding situations, companies must build the proper set of tools and processes required to seasonprovide adequate safety analytics capabilities.

\section{MODULAR HARDWARE AND SOFTWARE COMPONENTS}

Securityhave to be considered and implemented in every issue of IoT to higher manage the elements and modules of Internet-linked devices. Because attackers often exploit vulnerabilities in IoT gadgets when they have been implemented, groups must don't forget a protection paradigm just like the Forrester Zero Trust model for these gadgets.[11]

Where feasible, businesses should proactively set the stage via separating these devices to their very own network phase or VLAN. Additionally, technologies such as micro-kernels or hypervisors may be used with embedded systems to isolate the systems inside the event of a protection breach.[24]

\section{RAPID DEMAND IN BANDWIDTH REQUIREMENT}

A Palo Alto Networks Inc. Examine discovered that among November 2011 and May 2012, community visitors jumped seven-hundred\% on networks the seller found, largely due to streaming media, peer-to-peer packages and social networking. As greater devices hook up with the Internet, this quantity will keep growing. [12]

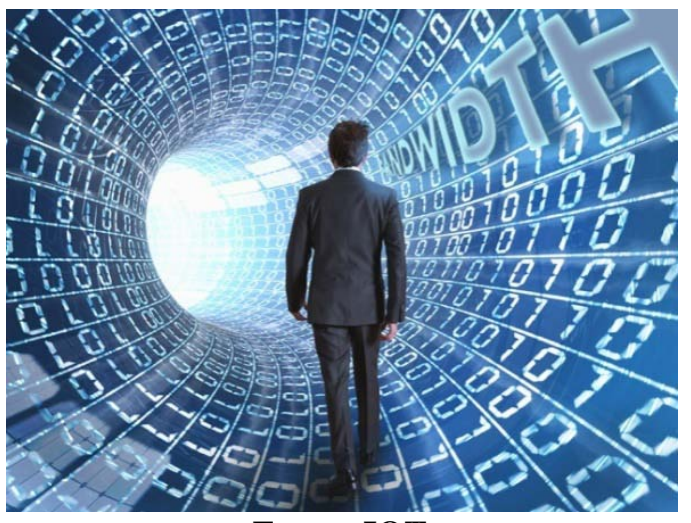

Future IOT

However, the elevated demand for the Internet will probably proliferate enterprise continuity risks. If important packages do not receive their required bandwidth, clients could have horrific reports, worker productivity will suffer and organisation profitability may want to fall.[14]

To make sure high availability of their services, enterprises need to do not forget including bandwidth and boosting traffic control and tracking. This not only mitigates enterprise continuity dangers, but additionally prevents potential losses. In addition, from the assignment-planning standpoint, organizations must perform capability planning and watch the growth charge of the network so that the increased demand for the specified bandwidth may be met.[15]

\section{CONCLUSION}

The Internet of Things has extraordinary capacity for the client as well as for enterprises, but no longer without chance. Information safety organizations should start arrangements to transition from securing PCs, servers, cell devices and traditional IT infrastructure, to managing a much broader set of interconnected items incorporating wearable devices, sensors and generation we will not even foresee presently. Enterprise safety groups should take the initiative now to analyze protection pleasant practices to comfy these rising gadgets, and be prepared to replace threat matrices and safety regulations as those gadgets make their manner onto company networks to permit gadget-tomachine verbal exchange, huge information series and numerous other uses. This accelerated complexity in the organization shouldn't be omitted, and risk modelling will be essential to make certain simple safety most important of confidentiality, integrity and availability are maintained in what will be an increasingly more interconnected virtual world.

\section{REFERENCES}

[1]. Pardeep Kumar and Hoon-Jae Lee - Security Issues in Healthcare Applications Using Wireless Medical Sensor Networks: A Survey 2012 sensors ISSN 1424-8220, www.mdpi.org/sensors

[2]. Liane Margarida RockenbachTarouco, Leandro MárcioBertholdo, Lisandro Zambenedetti Granville - 
Internet of Things in healthcare: Interoperatibility and security issues. Conference Paper· June 2012 DOI: $\quad$ 10.1109/ICC.2012.6364830 International Workshop on Mobile Consumer Health Care Networks, Systems and Services in 2012.

[3]. Internet of Things: a review of literature and productsTreffyn Lynch Koreshoff, Toni Robertson, Tuck Wah Leong 2013 - Proceedings of the 25th Australian Computer-Human Interaction Conference

[4]. Analysis of RFID Application for U-Healthcare System in Internet of Things Jung Tae Kim 2014 International Journal of Smart Home Vol.8 No.6 pp.131-142

[5]. Privacy and Security Issues in IoT Healthcare Applications for the Disabled Users a SurveyWassnaa AL-mawee 2015 Master's Thesis.

[6]. Towards an Analysis of Security Issues, Challenges, and Open Problems in the Internet of Things Md. Mahmud Hossain, MaziarFotouhi, and Ragib Hasan 2016-IEEE Xplore

[7]. The Internet of Things for Medical Devices Prospects, Challenges and the Way Forward Ashok Khanna and PrateepMisra $2016 \quad$ Tata Consultancy Services.

[8]. How the Internet of Things Is Revolutionizing Healthcare David Niewolny 2016

[9]. freescale.com/healthcare

[10]. Transforming healthcare through the Internet of Things: A Case Study M. Shankar Lingam and Dr. A. M. Sudhakara 2016 International

[11]. Conference on Intelligent Computing and Applications (ICICA 2016), Pune.

[12]. https://www.sparkfun.com/news/2196 by NPoole September 27, 2016 22:01 India Standard Time

[13]. IoT security (Internet of Things security), This definition is part of our Essential Guide: Managing information security amid new threats: A guide for CIOs, Posted by: Margaret Rouse, http://internetofthingsagenda.techtarget.com/definitio n/IoT-security-Internet-of-Things-security, 2016

[14]. Internet of Things: Challenges and Opportunities by Dr. Subhas Chandra Mukhopadhyay, Universidad Católica del Uruguay at IEEE Young Professionals Program Uruguay IEEE Circuits \& Systems Society Uruguay Chapter

[15]. Jim Chase, Strategic marketing, Texas Instruments (C) 2013 Texas Instruments Incorporated

[16]. Internet of Things (IoT): A vision, architectural elements, and future directions, JayavardhanaGubbi, RajkumarBuyyab,,SlavenMarusic and MarimuthuPalaniswami on February 2013, journal homepage: www.elsevier.com/locate/fgcs; Future Generation Computer Systems 29 (2013) 1645-1660.

[17]. Internet of Things (IoT) by Margaret Rouse, http://internetofthingsagenda.techtarget.com/definitio n/Internet-of-Things-IoT, 2016

[18]. http://www.businessinsider.com/iot-ecosysteminternet-of-things-forecasts-and-businessopportunities-2016-2?IR=T, BI Intelligence, Aug. 31, 2016

[19]. Internet of Things: A Review and Future Perspective, May 21, 2014 - TECHNOLOGY By N. K. Suryadevara and S. C. Mukhopadhyay

[20]. https://www.forbes.com/sites/gilpress/2017/03/20/6hot-internet-of-things-iot-securitytechnologies/\#3b37ab071b49

[21]. http://www.iotcentral.io/blog/gartner-identifies-thetop-10-internet-of-things-technologies-for

[22]. Marianne KolbasukMcGe,Executive Editor, Healthcare Info Security

[23]. Ajay Kumar, akumar_net2002@yahoo.com, http://searchsecurity.techtarget.com/ezine/Informatio n-Security-magazine/A-comprehensive-guide-tosecuring-the-Internet-of-Things 